\title{
SOROPOSITIVIDADE E LESÕES SUGESTIVAS DE BRUCELOSE EM BOVINOS ABATIDOS NO ESTADO DE TOCANTINS, BRASIL
}

\author{
L. Viana ${ }^{1}$, F. Baptista ${ }^{2}$, J. Teles ${ }^{1}$, A.P.C. Ribeiro ${ }^{2}$, C.P. Pigatto ${ }^{2}$ \\ ${ }^{2}$ Universidade Federal do Tocantins, Laboratório de Microbiologia Veterinária, CP132, CEP 77804970, Araguaína, \\ TO, Brasil. E-mail: baptista@uft.edu.br
}

\section{RESUMO}

\begin{abstract}
De outubro a dezembro de 2007, 845 amostras de sangue foram coletadas de 836 vacas (98,9\%) e nove touros $(1,1 \%)$, em um matadouro com inspeção federal no Estado do Tocantins. Cento e quarenta e duas amostras [(16,8\%) IC 95\% 14,3-19,4] tiveram reação positiva ao teste do antígeno acidificado e tamponado de Brucella abortus. Um touro foi positivo ao teste. Quinhentos e sessenta e um bovinos (66,3\%) procederam do Estado do Pará e $284(33,7 \%)$ do Estado do Tocantins. A prevalência de soropositividade foi de 17,2\% [IC (95\%) 13,6 - 19,9] e de 16,6\% [IC (95\%) 13,0 - 22,2] para o gado do Pará e Tocantins, respectivamente. Estas prevalências não são significativamente diferentes $(p>0,05)$. Nenhuma das vacas tinha registro de vacinação contra brucelose. Os exames "ante e post-mortem" não detectaram qualquer sinal ou lesão sugestiva à brucelose, como descargas vaginais, orquites, artrites ou bursites [(0,00\%) IC 95\% 0,00-0,43] em todos os bovinos da amostra. Esta situação, associada às altas prevalências da doença e à falta de diagnóstico da brucelose nos rebanhos, aumenta o número de bovinos infectados abatidos sob condições sanitárias inadequadas, o risco de contaminação dos trabalhadores e a colocação no mercado, sem restrição, de carne de animais infectados.
\end{abstract}

PALAVRA,S-CHAVE: Brucelose, zoonose, produtos de origem animal, saúde pública.

\begin{abstract}
SERUMPOSITIVITY AND LESIONSSUGGESTIVE OF BRUCELLOSIS IN CATTLESLAUGHTERED IN TOCANTINSSTATE, BRAZIL. From October to December 2007,845 blood samples were collected from 836 cows $(98.9 \%)$ and nine bulls $(1.1 \%)$, in a slaughterhouse with federal inspection in the state of Tocantins. One hundred and forty-two samples [(16.8\%) 95\% CI 14.3-19.4] had positive reaction to the plate agglutination test carried out with acidified and buffered antigen of Brucella abortus. One bull was positive to the test. Five hundred and sixty one bovines came from the State of Pará (66.3\%) and 284 (33.7\%) came from the State of Tocantins. The prevalence of serum positivity was 17.2\% [CI (95\%) 13.6 - 19.9] and 16.6\% [CI (95\%) 13.0 - 22.2] for cattle came from Pará and Tocantins, respectively, with no significant difference between these frequencies $(p>0.05)$. None of the cows had record of vaccination against brucellosis. "Ante and post-mortem" examinations could not find any sign or lesion attributable to brucellosis, such as vaginal discharges, joint inflammation or bursitis [(0.00\%) 95\% CI 0.00-0.43] in all bovines sampled. This situation, coupled with the high prevalence of the disease and the lack of brucellosis diagnostic at herds, increases the number of infected cattle slaughtered under inadequate sanitary conditions, the risk of contamination of workers and placing on the market, without restriction, the meat from infected animals.
\end{abstract}

KEY WORDS: Brucellosis, zoonosis, animal products, cattle, slaughterhouse.

A brucelose é uma doença bacteriana de grande importância para a economia pecuária e para a saúde pública por se tratar de uma zoonose. Possui distribuição mundial e, no Brasil, levantamentos epidemiológicos revelam diferentes prevalências regionais. POESTER et al. (2002) relataram que a prevalência da doença no Brasil varia de 2,5\% a 7,5\%.
De acordo com estes autores, as prevalências nas regiões Sul, Sudeste, Centro-Oeste e Nordeste eram de $4 \%, 7,5 \%, 6,8 \%$ e 2,5\%, respectivamente. A região Norte, da qual o Estado do Tocantins faz parte, apresentou $4,1 \%$ de positividade. $\mathrm{Na}$ decorrência dessas prevalências, embora possam ser admitidas amplas variações se forem considerados os reban-

${ }^{1}$ Instituto Quallitas, Campinas, SP, Brasil.

Arq. Inst. Biol., São Paulo, v.77, n.3, p.517-520, jul./set., 2010 
hos individualmente, a situação epidemiológica e, consequentemente, a estratégia oficial de combate a brucelose é a mesma em todo o território brasileiro, exceção feita ao Estado de Santa Catarina que apresenta prevalência inferior a 1\%., (SIKUSAWA etal., 2009). O Programa Nacional de Controle e Erradicação da Brucelose e da Tuberculose (PNCEBT), do Ministério da Agricultura, Pecuária e Abastecimento do Brasil (MAPA), o qual foi instituído em 2001, relatou que o combate à brucelose centra-se na vacinação de bezerras entre os três e os oito meses de idade e no controle do trânsito animal, sendo de livre adesão o saneamento dos rebanhos (BRASIL, 2009).

Nos bovinos, a espécie envolvida é a Brucella abortus (NIELSEN; DunCAN, 1990). A infecção apresenta evoluçãocrônica eacometeanimais de todas asidades, porém é mais frequente em indivíduos sexualmente maduros. A principal porta de entrada da brucelose em bovinos é a digestiva, podendo também dar-se na reprodução, por monta natural, mas principalmente por inseminação artificial (MONTEIRO et al., 2006). A entrada do agentenas criações ocorre, principalmente, através de fêmeas infectadas com ou sem histórico anterior de abortamento (BEER, 1988; PolETto et al., 2004).

Oserhumano podeseinfectar pelaingestãodeleitee derivados contaminados, manipulaçãodecarnes, fetos e membranas fetais, sangue e outros tecidos contendo o agente (REBHUM, 2000). Esta doença possui caráter profissional, pois médicos veterinários, vaqueiros, peões, magarefes, agentes de inspeção e laboratoristas estão mais sujeitos à infecção (REBHUM, 2000), a qual pode ainda ser acidental por manuseio e aplicação da vacina viva da B. abortus cepa B19 (AlmEIDA et al., 2000). MAFRA (2008) relatou que, as Brucella spp. sobrevivem em carnes conservadas em câmaras frigoríficas, podendo por isso representar risco de contaminação a manipuladores ou consumidores de carne.

Baseadona verificação desinais ou delesões, pouco frequentes e difíceis de detectar nos exames "ante e post-mortem", o diagnóstico da brucelose bovina em matadouro é pouco seguro. Como o principal sinal da enfermidadeéo abortamentono terço final da gestação (Paulin; Ferreira Neto, 2003) e este ocorre nas propriedades, outros sinais como febre, secreção vaginal, inflamações elesões articulares e bursites, sendo pouco frequentes, mesmoem rebanhoscomaltas prevalências da doença, têm valor reduzido na identificação de animais infectados nos matadouros. Por outro lado, todos os sinais acima referidos podem ser devidos a outras causas. Vários trabalhos tentam estabelecer relação entre bursite e deteç̧ão direta ou indireta de Brucellasp. em bovinoscom essa lesão. A frequência da Brucella sp. em bovinos com bursite apresenta ampla variação, embora seja sempre baixa a prevalência da lesão nos contingentes de abate estudados. AlmEIDA et al. (2000) encontraram, em 26.800 bovinos abatidos em matadouro com Inspeção Federal, uma prevalência de bursitede 0,14\% [IC95\% -0,10a 0,20]; de30animaiscom bursite, 13,3\% foram soropositivos para brucelose. No Estado do Pará, Freitas; OliveIra (2005) encontraram uma prevalência de bursite em matadouro de $0,10 \%$ [IC 95\% - 0,07 a 0,13]; todos os exsudados das bursites deram sorologia positiva para brucelose. ANGREvEs et al. (2007), em 15 amostras de material de bursites em bovino, evidenciaram Brucella sp. em apenas uma amostra (6,6\%). Estes autores, citando PARDI et al. (2001), afirmaram que, embora a bursitecervical sugira infecção brucélica, a causalidade dessa lesão necessita ainda de esclarecimentos.

Este trabalho tevecomo objetivoevidenciaro riscoà saúdedos trabalhadorese dosconsumidoresno padrão atual de abate, o qual não exige certificação de propriedadesedebovinos, noquetangeao seu estadodesaúde relativo à brucelose, determinando-se por sorologia a frequência da doença em um matadouro. Ao mesmo tempo procurou-seevidenciaracapacidadediagnóstica dos exames "ante e post-mortem" na mesma amostra de bovinos, determinando-se a frequência de sinais ou de lesões sugestivas da enfermidade.

A pesquisa foi feita entre outubro e dezembro de 2007, em um frigorífico com inspeção federal e habilitado para exportação, localizado no Município de Colinas, Estado de Tocantins.

A média mensal de animais abatidos era de 4.320. Combasenesta população, uma amostra mínima de721 animaisfoicalculada, considerando-seuma prevalência esperada de $10 \%$, precisão de $2 \%$ enível designificância de $95 \%$. Com um adicional de $10 \%$ para cobertura de eventuais perdas, a amostra passou para 793 bovinos. Foi possível coletar amostras em 11 ocasiões com um total previsto de abate nesses dias de 1.584 animais. Como a amostra de 721 bovinos corresponde a cerca de $50 \%$ da previsão de abate nas 11 ocasiões definidas para a coleta, este percentual foi utilizado para determinação do número de amostras a serem coletadas em cada ocasião. Os animais foram selecionados por amostragem sistemática na linha de abate.

Ao exame "ante e post mortem", foram procurados sinais ou lesões sugestivos da infecção brucélica, como secreções vaginais, aumento do tamanho dos testículos, aumento de tamanho ou lesões articulares e bursites, de acordo com o RIISPOA (BRASIL, 1952). Foi ainda pesquisada a existência de registro de vacinação ou marca no couro de cada animal indicando a sua condição vacinal. O sangue foi coletado da jugular durante a sangria em frascos de vidro sem anticoagulante. Após coagulação, osfrascoscomas amostras desangue foram acondicionados em isopor com gelo reciclável e enviados ao Laboratório de Microbiologia e Imunologia Veterinária da Escola de Medicina Veterinária e Zootecnia daUniversidadeFederal do Tocantins (UFT). O soro foi mantido à temperatura de menos $20^{\circ} \mathrm{C}$ até o momento do exame e todas as análises foram feitas em até 72 horas após a chegada das amostras. 
Tabela 1 - Prevalência de bovinos soropositivos para brucelose em matadouro frigorífico no Estado do Tocantins, Brasil, 2007.

\begin{tabular}{lccccc}
\hline Estado & № de bovinos & $\%$ & Soropositivos & Prevalência (\%) & IC (95\%) \\
\hline Pará & 561 & 63,4 & 93 & 16,6 & $13,6-19,9$ \\
Tocantins & 284 & 36,6 & 49 & 17,2 & $13,0-22,2$ \\
\hline Total & 845 & 100 & 142 & 16,8 & $14,3-19,4$ \\
\hline
\end{tabular}

A pesquisa de anticorpos anti B. abortus foi realizada utilizando-se antígeno acidificado e tamponado conforme o protocolo recomendado pelo MAPA (BRASIL, 2009). Com o programa EpiInfo 604 criou-se uma base de dados a qual foi alimentada com informação sobre os animais amostrados: estado e município de procedência, sexo, categoria (vaca, touro, boi, novilho, novilha), estado vacinal, sinais e lesões compatíveis com brucelose nos exames "ante e post mortem" e resultados dos exames sorológicos. Com o mesmo programa foram extraídas e comparadas freqüências das variáveis do estudo. As comparações foram feitas pelo cálculo do $\mathrm{c}^{2}$, utilizando-se o nível de significância de $95 \%$.

Os resultados do diagnóstico sorológico deste trabalho são apresentados na Tabela 1. Foram analisados 845 soros de bovinos abatidos entre outubro e dezembro de 2007 , sendo 836 vacas $(98,9 \%)$ e nove touros (1,1\%); 561 bovinos (66,3\%) eram de cinco municípios do Estado do Pará e 284 (33,7\%) de 12 municípios do Estado do Tocantins. Dos 845 bovinos da amostra, 141 vacas e um touro [16,8\% (IC95\% 14,3 a 19,5)] resultaram soropositivos para brucelose. Nenhuma das vacas trazia indicação de seu estado vacinal. Nenhum dos animais da amostragem apresentou sinais sugestivos de brucelose nos exames ante e "post-mortem" [0,00\% (IC95\% - 0,00 a 0,43].

Prevalência de soropositividade para brucelose foi de $16,6 \%$ para o gado do Pará e de 17,2\% para os animais do Tocantins, não havendo diferença significativa entre as duas prevalências $-\mathrm{c}^{2}=0,06 \mathrm{e}$ $p=0,8$ - (Tabela 1). Embora o padrão de abate segundo categoria de bovino (vaca, touro, novilho e novilha) possa variar de acordo com o frigorífico, é de se prever que este problema se repita em outros matadouros do Estado de Tocantins e de outros estados brasileiros.

De acordo com o RIISPOA, mesmo na sua nova versão recentemente submetida à consulta pública, animais soropositivos para brucelose têm restriçãono aproveitamento de suas carcaças caso se apresentem febris ao exame "ante-mortem" ou tenham lesões sugestivas de infecção brucélica no exame "postmortem". Este trabalho, mesmo com uma amostra pequena, de 845 bovinos, $16,8 \%$ dos bovinos foram soropositivos para brucelose sem que em nenhum deles tivesse sido possível detectar qualquer sinal sugestivo da doença. A prevalência de sinais sugestivos de brucelose $[0,00 \%$ (IC95\% - 0,00\% a 0,43\%)], ao lado da prevalência sorológica acima indicada, mostra que o diagnóstico clínico da brucelose em matadouro tem reduzida eficácia no controle do risco que a doença pode representar para os trabalhadores. Também não é critério seguro de julgamento sanitário por permitir a liberação, para consumo direto, de um grande número de carcaças de animais que, por sorologia, podem ser considerados infectados. Esta apreciação não é prejudicada pelo fato de se ter utilizado um teste de rastreio de alta sensibilidade e, como tal, poder fornecer alguns falso-positivos.

A utilização de critério mais seguro e prático de diagnóstico da brucelose em animais destinados ao abate pode ser uma forma de se reduzirem os riscos acima apontados e se proteger melhor a saúde de trabalhadores e de consumidores. Isto reduziria o número de bovinos infetados nos contingentes gerais de abate, expondo menos os trabalhadores e aumentando a qualidade sanitária da carne destinada a consumo direto. MAFrA (2008) relatou que as Brucella spp. sobrevivem em carnes conservadas em câmaras frigoríficas. Para Almeida et al. (2000), as pessoas podem se contaminar por ingestão de leite ou carne crus ou malpassados, manuseio de produtos contaminados ou manejo de animais infectados.

Odiagnóstico clínico da brucelose praticado pela inspeção veterinária nos frigoríficos, na ausência de um critério diagnóstico mais sensível e específico, tem valor reduzido na proteção da saúde dos trabalhadores e na promoção da qualidade sanitária da carne.

\section{REFERÊNCIAS}

ALMEIDA, L.P.; REIS, D.O.; GERMANO, P.M.L. Brucelose em bovinos com bursite cervical diagnosticada em abatedouro sob inspeção federal. Ciência Rural, v.30, p.287-291, 2000.

ANGREVES, G.M.; ROCHA, P.R.D; GASPARETTO, N.D.; FERREIRA, E.V.; ALBERTON, E.L.; ROCHA, K.C.; SOUZA, A.C.P.; NAKAZATO, L.; DUTRA, V.; COLODEL, E.M. Caracterização morfológica e investigação etiológica de bursite cervical em bovinos abatidos no Estado de Mato Grosso. Mato Grosso: Universidade Federal do 
Mato Grosso, 2007. Disponível em: <http:/ / www.ufmt. br/patologiavet/enapave2007/bursite.pdf $>$. Acesso em: 3 ago. 2010 .

BEER, J. (Ed.). Doenças infecciosas em animais domésticos. São Paulo: Roca, 1988. 380p.

BRASIL, Ministério da Agricultura, Pecuária e Abastecimento. Regulamento da Inspeção Industrial e Sanitária dos Produtos de Origem Animal (RIISPOA). 1952. Disponível em: <http:/ / www.agricultura.gov.br>. Acesso em: 30 ago. 2008.

BRASIL. Ministério da Agricultura, Pecuária e Abastecimento. Manual Técnico do Programa Nacional de Controle e Erradicação da Brucelose e da Tuberculose Bovina (PNCEBT). 2003. Disponível em: <http:/ / www.agricultura.gov.br/ das/dda/propostas.htm>. Acesso em: 3 ago. 2010.

BRASIL. Ministério da Agricultura, Pecuária e Abastecimento. Programa Nacional de Controle e Er-radicação da Brucelose e da Tuberculose Bovina (PNCEBT). 2009. Disponível em: <www.agricultura.gov.br>. Acesso em: 3 ago. 2010.

FREITAS, J.A.; OLIVEIRA, J.P. Pesquisa de Infecção Brucélica em Bovídeos Abatidos Portadores de Bursite. Arquivos do Instituto Biológico, São Paulo, v.72, n.4, p.427433, 2005.

MAFRA, P. Impacto da brucelose no ambiente e saúde pública - estratégias de controle em zonas endêmicas. Ciências da Natureza. 2008. Disponível em: <www.catraios.pt/ profs/salarecursos/matcn/brucelose.pdt>. Acesso em: 1 set.2008

MONTEIRO, L.A.R.C.; PELLEGRIN, A.O.; ISHIKAWA, M.M.; OSÓRIO, A.L.A.R. Investigação epidemiológica da brucelose bovina em um estrato do Estado de Mato Grosso do Sul. Pesquisa Veterinária Brasileira, v.26, p.217222, 2006.

NIELSEN, K.; DUNCAN, J.R. Animal brucellosis. Boca Raton: CRC Press, 1990. 464p.

PARDI, M.C.; SANTOS, I.F.; SOUZA, E.R.; PARDI, H.S. Ciência, higiene e tecnologia da carne. 2.ed, UFG: Goiânia, 2001.

PAULIN, L.M.; FERREIRA NETO, J.S. (Ed.). O Combate à brucelose bovina: situação brasileira. Jaboticabal: Funep, 2003. 154p.

POESTER, F.P.; GONÇALVES, V.S.P.; LAGE, A.P. Brucellosis in Brazil. Veterinary Microbiology, v.90, p.5562, 2002.

POLETTO, R.; KREUTZ, L.C.; GONZALES, J.C.; BARCELLOS, L.J.G. Prevalência de tuberculose, brucelose e infecções víricas em bovinos leiteiros do município de Passo Fundo, RS. Ciência Rural, v.34, p.595-598, 2004.

REBHUM, W.C. (Ed.). Doenças de gado leiteiro. São Paulo: Roca, 2000. 140p.

SIKUSAWA, S.; AMAKU, M.; DIAS, R.A.; FERREIRA NETO, J.S.; MARTINS, C.; GONÇALVES, V.S.P.; FIGUEIREDO, V.C.F.; LÔBO, J.R.; FERREIRA, F. Situação epidemiológica da brucelose bovina no Estado de Santa Catarina. Arquivo Brasileiro de Medicina Veterinária e Zootecnia, v.61, p.103-108, 2009.

Recebido em 29/5/09 Aceito em 3/8/10 